\title{
PLANOSSOLOS E GLEISSOLOS UTILIZADOS NA FABRICAÇÃO DE CERÂMICA ARTESANAL NO SEMIÁRIDO DE MINAS GERAIS
}

\author{
Diana Ferreira de Freitas(1), João Carlos Ker(2), Raphael Bragança Alves Fernandes(2) e \\ Maurício Paulo Ferreira Fontes(2)
}

(1) Universidade Federal Rural de Pernambuco, Unidade Acadêmica de Serra Talhada, Serra Talhada, Pernambuco, Brasil.
(2) Universidade Federal de Viçosa, Departamento de Solos, Viçosa, Minas Gerais, Brasil.
* Autor correspondente.
E-mail: freitasdf.solos@gmail.com

\section{RESUMO}

O conhecimento etnopedológico tem fornecido informações importantes sobre o modo de vida das populações rurais a respeito de suas tradições ancestrais, como a arte de elaborar peças artesanais a partir do barro advindo de solos com características próprias a esse uso. O objetivo deste trabalho foi avaliar física, química e mineralogicamente Planossolos e Gleissolos explorados para a produção de artefatos de cerâmica artesanal em Minas Gerais. Nos barreiros, foram coletados dois perfis de Planossolos (P1 e P2) e um Gleissolo (P3) usados como matéria-prima na produção artesanal de cerâmica. Foram realizadas análises físicas e químicas, limites de liquidez (LL) e plasticidade (LP), índice de plasticidade (IP) e de atividade coloidal (IA), além da mineralogia da fração argila. Os horizontes selecionados pelos ceramistas para a fabricação de cerâmica artesanal (BA, Btg e BCg, do P1; Btg1 e Btg2, do P2; e C2g e C3g, do P3) apresentaram os maiores teores de argila e silte, IP e IA, importantes para a qualidade final da cerâmica. O horizonte $\mathrm{Cg}$ do perfil P1 possui potencial de ser utilizado para a produção artesanal, em virtude do seu IP, superior aos dos horizontes normalmente usados, além dos teores de argila, silte e areia fina e suas características mineralógicas. A proporção ideal das frações areia, silte e argila e a porcentagem de matéria orgânica na definição de um bom material para cerâmica são difíceis de estabelecer e variam principalmente em razão de aspectos quantitativos e qualitativos da argila nos solos.

Palavras-chave: etnopedologia, solos hidromórficos, uso não agrícola do solo. 


\title{
ABSTRACT: PLANOSOLS AND GLEYSOLS USED IN THE MANUFACTURE OF HANDCRAFTED POTTERY IN THE SEMIARID REGION OF MINAS GERAIS
}

\begin{abstract}
Ethnopedological knowledge has provided important information about the way of life of rural people and their traditions, like the craft of making pieces of pottery from suitable soils. The objective of this study was to evaluate the physical, chemical, and mineralogical properties of Planosols and Gleysols used in the production of handcrafted pottery artifacts in the State of Minas Gerais, Brazil. In the clay pits, two profiles of Planosol soil (P1 and P2) and one of Gleysol soil (P3) used as raw material in the production of handcrafted pottery were collected. Physical and chemical properties, liquidity limits (LL), plasticity limits (LP), plasticity index (PI), and colloidal activity (IA) were analyzed, as well as clay mineralogy. The horizons selected by potters to manufacture handcrafted pottery (BA, Btg, and BCg for P1; Btg1 and Btg2 for P2; and C2g and C3g for P3) showed higher clay and silt, IP, and IA contents, important for the final quality of the pottery. The Cg horizon of the P1 profile has potential for craft production due to its $I P$, which is greater than the horizons normally used, as well as its clay, silt, and fine sand contents, and mineralogical characteristics. The ideal proportion of sand, silt, and clay and the percentage of organic matter are difficult to establish in defining good material for pottery; they vary mainly as a result of the type and proportion of clay found in the soils.
\end{abstract}

Keywords: ethnopedology, hydromorphic soils, non-agricultural use of the soil.

\section{INTRODUÇÃO}

O conhecimento empírico das populações rurais e indígenas tem sido cada vez mais reconhecido e valorizado por ser fonte de informações e produtos que podem ser utilizados por pesquisadores e pela sociedade em geral. Esse reconhecimento se deve ao acúmulo de experiências no desenvolvimento de técnicas, estratégias e uso diferenciado de recursos naturais como os solos, viabilizando a permanência e sobrevivência dessas populações no meio rural. Isso implica que o conhecimento popular, embora sem base científica, possui sua própria racionalidade e complexidade (Cardoso e Resende, 1996; Alves et al., 2005).

A etnopedologia abrange os sistemas empíricos do conhecimento do solo e da terra por populações rurais e indígenas, analisando o solo como um recurso natural ecológico e econômico (Barrera-Bassols e Zinck, 2003). Assim, utiliza-se das experiências e observações dos agricultores para identificar e estratificar áreas homogêneas dentro de uma propriedade. A pesquisa científica pode utilizar esse conhecimento para solucionar problemas cotidianos em pequenas propriedades, além de reunir critérios que poderiam ser utilizados na classificação local do solo, como caracterizar níveis categóricos mais baixos (séries) nos sistemas de classificação de solos, como no SiBCS, mesmo que a informação não possa algumas vezes ser extrapolada para outros locais (Queiroz e Norton, 1992; Talawar e Rhoades, 1998; Correia et al., 2007).

O uso múltiplo do solo é uma característica particular das populações rurais, ribeirinhas e indígenas, seja para o uso agrícola ou não; por exemplo, para a confecção de cerâmica artesanal em Pasmado, distrito do município de Itaobim, Minas Gerais (Ollier et al., 1971; Browman e
Gundersen, 1993; Schaefer et al., 1997; Barrios e Trejo, 2003; Osbahr e Allan, 2003; Correia et al., 2004; Alves et al., 2005). Os solos utilizados como matéria-prima para a fabricação do artesanato de cerâmica em Pasmado, Médio Jequitinhonha, MG, são popularmente conhecidos como "barreiros", em referência ao local onde se acumula e se extrai "barro" (Bueno, 1985), normalmente destinados à produção de pastagens utilizadas para a alimentação de bovinos e caprinos. Em geral, apresentam coloração acinzentada, localizando-se em pequenas extensões territoriais nos terraços do rio Jequitinhonha, aparecendo normalmente como inclusões nas unidades de mapeamento dos Neossolos Flúvicos da área. Estão em áreas de topografia plana ou deprimida e referem-se normalmente aos horizontes B e C de Planossolos e Gleissolos, respectivamente (Brasil, 1970, 1987).

A tradição da arte oleira encontra-se firmada no estilo de vida das populações rurais do Médio Jequitinhonha, influência deixada por tribos indígenas, como Botocudos e Trococós, que habitavam todo o nordeste de Minas Gerais, sul da Bahia e norte do Espírito Santo. A produção de peças de cerâmica na região se iniciou com a confecção de simples objetos artesanais pelas mulheres, como vasos, moringas, vasilhas e panelas utilizadas no seu cotidiano, atribuindo a adjetivação de "paneleiras" a essas artesãs. Essa atividade se dá pela necessidade de melhoria da renda familiar, principalmente nos períodos de seca prolongada, em que a produção agrícola se torna insuficiente para suprir a demanda financeira da família. O trabalho com cerâmica é quase que exclusivamente feminino, com raras exceções entre os homens. Assim, a mulher, antes considerada com papel secundário de ajudante da família, encontra na produção artesanal uma forma de contribuição ativa para as despesas domésticas. 
A mineração é uma das mais importantes modalidades de exploração dos recursos naturais, tanto do ponto de vista econômico quanto aos aspectos negativos que normalmente são observados no meio físico. A extração do "barro" para a fabricação das peças cerâmicas é de grande importância social e econômica para a comunidade de Pasmado, porém provoca degradação ambiental com desconfiguração da paisagem local, ainda que nessas áreas o uso agrícola seja limitado, principalmente em razão de problemas com sais solúveis e drenagem deficiente. Logo, pode-se considerar que esses solos são recurso finito como matéria-prima ("barro") na utilização da atividade de cerâmica.

Tendo em vista a finita disponibilidade de matéria-prima para o uso cerâmico e o pouco conhecimento das características desses solos para fins não agrícolas, o objetivo deste trabalho foi caracterizar física, química e mineralogicamente Planossolos e Gleissolos usados para a fabricação de cerâmica artesanal em Pasmado, distrito do município de Itaobim, MG, tradicionalmente desenvolvida pela comunidade, para auxiliar no uso alternativo de outras camadas de solo ainda não utilizadas no processo produtivo.

\section{MATERIAL E MÉTODOS}

\section{Meio físico}

Aárea de estudo localiza-se na comunidade rural de Pasmado, situada aproximadamente a $17 \mathrm{~km}$ a oeste do município de Itaobim, próxima à divisa do município de Itinga, Médio Jequitinhonha. Foram selecionados dois "barreiros", identificados como "barreiro 1 e barreiro 2" (Figura 1). No primeiro, localizado a $4 \mathrm{~km}$ da comunidade de Pasmado, sentido Itaobim, foram coletados dois perfis de Planossolo Háplico eutrófico típico (P1 e P2). No segundo, a $2,8 \mathrm{~km}$ da mesma comunidade, sentido Itinga, coletou-se um perfil de Gleissolo Háplico $\mathrm{Tb}$ eutrófico solódico (P3), descritos e classificados de acordo com Santos et al. (2005) e Embrapa (2013), respectivamente.

O clima é Bsw (Köppen), caracterizado como continental seco e quente, com temperaturas médias elevadas no inverno e verão, e média de precipitações pluviais da ordem de $705 \mathrm{~mm}$ anuais (ANA, 2001). As chuvas se concentram nos meses de primavera-verão (outubro a abril), com maiores precipitações nos meses de dezembro, janeiro e fevereiro.

A vegetação de caatinga na região se distingue das demais formações desse mesmo bioma tanto pelos aspectos fisionômicos como florísticos (Brasil, 1970). É um tipo de formação vegetal muito modificada com árvores bastante espaçadas, indicando vegetação secundária e evidenciando

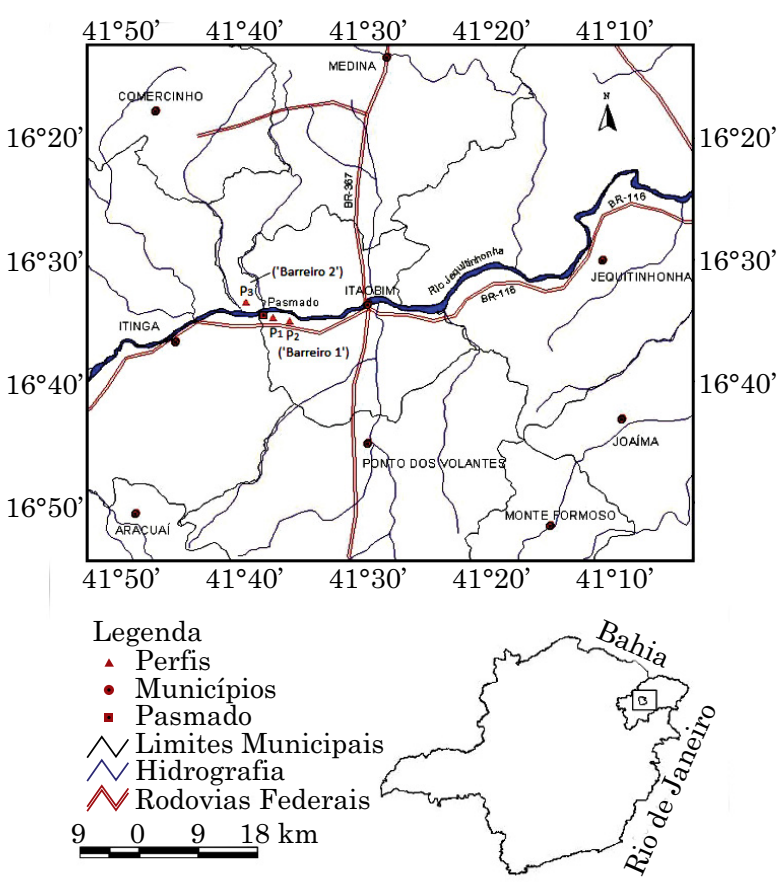

Figura 1. Localização da área de estudo no distrito de Pasmado, município de Itaobim, Médio Jequitinhonha, MG.

os efeitos da atividade extrativista para lenha. No levantamento de solos elaborado pela Equipe de Pedologia e Fertilidade do Solo, descreve-se a presença de cactáceas e bromeliáceas, indicando que no passado a cobertura vegetal foi mais diversificada, com muita extração de madeiras consideradas nobres como a aroeira (Astronium fraxinifolium) e braúna (Melanoxylon brauna).

A geologia da região compreende desde rochas cristalinas (granito-gnáissico e granitos Neoproterozoicos), além de coberturas detrito-lateríticas (Terciário) e sedimentos Quaternários arenoargilosos, que acompanham as calhas fluviais do rio Jequitinhonha e de seus afluentes (CPRM, 2004).

Geomorfologicamente, a área está enquadrada dentro da Depressão do Médio Jequitinhonha, delimitada pelo Planalto do Jequitinhonha. São compartimentos deprimidos do vale do rio Jequitinhonha, comportando rochas intrusivas do Complexo Medina (Brasil, 1987) e extensos terraços fluviais decorrentes dos processos morfoclimáticos que os formaram (Brasil, 1970). Caracteriza-se pela dominância de formas aplainadas que evidenciam remanejamentos de material coluvial deslizado das encostas dos relevos circunjacentes. Esse material constitui rampas atingidas por uma dissecação incipiente formando lombas, localmente marcadas por afloramentos de rochas graníticas, conhecidas como lajedos (Amaral et al., 2004). 


\section{Análises laboratoriais}

As análises físicas e químicas foram realizadas na terra fina seca ao ar (TFSA). A composição granulométrica e argila natural, os cálculos do grau de floculação e a relação silte/argila foram definidos de acordo com Embrapa (1997).

As determinações dos limites de consistência LL (limite de liquidez) e LP (limite de plasticidade) foram efetuadas de acordo com a ABNT NBR 6459/84 (1984a) e NBR 7180/84 (1984b). Para isso, cerca de $350 \mathrm{~g}$ de solo foram transferidos para peneira com malha de 0,42 $\mathrm{mm}$. Cada amostra foi transferida para placa de vidro, com uma face esmerilhada, e submetida à mistura com água destilada. Adicionaram-se alíquotas de água destilada, agitando-se continuamente com auxílio de espátula por 10 a 15 min. Esse tempo variou de acordo com a porcentagem de argila para formar uma pasta uniforme, homogênea e relativamente consistente. Após completa homogeneização, foram determinados os limites de liquidez (LL) e de plasticidade (LP); o índice de plasticidade (IP) foi encontrado pela diferença entre ambos (IP = LL - LP). A partir dos valores de IP, os solos foram enquadrados nas classes de plasticidade de acordo com o estabelecido por Caputo (1994).

Com auxílio dos valores de índice de plasticidade (IP) e teor de argila (dag kg-1) de cada solo, foi calculado o índice de atividade coloidal (IA), classificando as argilas em: inativas $(\mathrm{IA}=0,75)$, de atividade normal $(0,75>\mathrm{IA}>1,25)$ e ativas $(\mathrm{IA} \geq 1,25)$ (Skempton, 1953).

As análises químicas de fertilidade consistiram de $\mathrm{pH}$ em água e em KCl $(1: 2,5)$, carbono orgânico total (Embrapa, 1997) e $\mathrm{Ca}^{2+}{\mathrm{e} \mathrm{Mg}^{2+}}^{2+}$ extraídos por $\mathrm{KCl} 1 \mathrm{~mol} \mathrm{~L}{ }^{-1}$, quantificados por espectrofotometria de absorção atômica e $\mathrm{Na}^{+} \mathrm{e} \mathrm{K}^{+}$ com solução de Mehlich-1 ( $\mathrm{HCl} 0,05 \mathrm{~mol} \mathrm{~L}^{-1}+\mathrm{H}_{2} \mathrm{SO}_{4}$ $0,0125 \mathrm{~mol} \mathrm{~L}^{-1}$ ) e determinadas por fotometria de emissão de chama. Todo o procedimento foi com base em métodos constante em Embrapa (1997). A partir desses dados, foram calculadas a soma de bases (valor S), atividade da fração argila $\left(\mathrm{CTCr}=\mathrm{CTC}_{\mathrm{pH} 7,0} \%\right.$ argila $)$, saturação por bases (V) e saturação por sódio (PST).

As formas de $\mathrm{Fe}$ foram extraídas pelo método do ditionito-citrato-bicarbonato (DCB) (Mehra e Jackson, 1960) e oxalato ácido de amônio (McKeague e Day, 1966) de pastas umedecidas de TFSA, após aquecimento em mufla, nas temperaturas de $100^{\circ} \mathrm{C}$, $350{ }^{\circ} \mathrm{C}$ e $550{ }^{\circ} \mathrm{C}$, e determinadas por espectrometria de absorção atômica.

A análise mineralógica da fração argila foi executada pela técnica de difração de raios-X em difratômetro Rigatu Radiation Shield, com tubo de cobalto (Co Ka) na faixa entre 4 e $45^{\circ} 2 \theta$ em intervalos de $0,01^{\circ} 2 \theta$ a cada segundo, após desferrificação e preparação das lâminas orientadas, saturadas com $\mathrm{K}$, nas temperaturas de $25{ }^{\circ} \mathrm{C}, 350{ }^{\circ} \mathrm{C}$ e $550{ }^{\circ} \mathrm{C}, \mathrm{Mg}$ e $\mathrm{Mg}+$ etileno glicol (Whitting e Allardice, 1986).

\section{RESULTADOS E DISCUSSÃO}

\section{Descrição morfológica}

De acordo com as características morfológicas, os solos são pouco profundos e a sequência de horizontes para os perfis $\mathrm{P} 1$ e P2 são, respectivamente, A-BA-Btg-BCg-Cg e A-E-Btg1-Btg2-BCg, enquanto para o P3 é A-C1g-C2g-C3g (Quadro 1).

A diferenciação de cor nos perfis de Planossolos e Gleissolo, embora não acentuada, está condizente com o caracterizado para essas classes de solos. Nos horizontes mais profundos dos Planossolos P1 e P2, e em todo o perfil do Gleissolo P3, houve desenvolvimento de coloração $2,5 \mathrm{Y}$, própria de horizontes gleizados, em consequência da modificação na natureza e quantidade de óxidos de Fe (Scatolini e Moniz, 1992).

Os horizontes A dos perfis P1 e P2 ("barreiro 1"), pelos critérios de cor, espessura e carbono orgânico adotados pelo SiBCS (Embrapa, 2013), foram classificados como A moderado; do P3 ("barreiro 2") classificou-se como A fraco $(<5 \mathrm{~cm})$. Os Planossolos P1 e P2 encontram-se em relevo plano, próximos a lajedo de granito, rocha comumente encontrada aflorando em toda a região do Médio Jequitinhonha. O Gleissolo (P3) situa-se em pequena várzea, decorrente da dinâmica de deposição dos sedimentos aluviais. Toda a área ao seu entorno, diferentemente dos Planossolos, no período da coleta, encontrava-se alagada, com presença dominante da espécie vegetal "cebolinha do brejo".

A diferença nos teores de argila entre o horizonte superficial, de textura mais arenosa, e subsuperficial, de média a argilosa, caracterizou mudança textural abrupta e presença de horizonte Bt nos perfis $\mathrm{P} 1$ e P2 (Quadro 1). Nesse caso, o horizonte Bt funciona por vezes como "pã", pela formação de lençol de água suspenso e periódico, principalmente nos períodos das maiores precipitações pluviais. Suas cores acinzentadas se devem às condições redutoras decorrentes do excesso de água, com estrutura em blocos subangulares fortemente desenvolvida; no caso do P2, observou-se formação de estrutura em colunas. No perfil P2, no topo do horizonte Btg1, foi nítido o maior endurecimento provocado pela translocação de argila do horizonte E, além dos elevados teores de $\mathrm{Na}^{+}$.

Ainda no perfil P2, encontrou-se horizonte E álbico aos $17 \mathrm{~cm}$ de profundidade, com $3 \mathrm{~cm}$ de espessura, cor do solo úmida de 10YR 4,5/2 (bruno-acinzentado escura) e seca de 10YR 6/2 (cinzento-brunado clara). 
Quadro 1. Descrição morfológica dos perfis de solos utilizados na fabricação de cerâmica artesanal no distrito de Pasmado, município de Itaobim, Minas Gerais

\begin{tabular}{|c|c|c|c|c|c|c|c|c|c|}
\hline \multirow{2}{*}{ Horiz. } & \multirow{2}{*}{ Prof. } & \multicolumn{2}{|c|}{ Cor $^{(1)}$ (Munsell) } & \multirow{2}{*}{ Textura } & \multirow{2}{*}{ Estrutura } & \multicolumn{3}{|c|}{ Consistência } & \multirow{2}{*}{ Trans. ${ }^{(2)}$} \\
\hline & & Úmida & Seca & & & Seca & Úmida & Molhada & \\
\hline & $\mathrm{cm}$ & & & & & & & & \\
\hline \multicolumn{10}{|c|}{ P1 - Planossolo Háplico eutrófico típico } \\
\hline A & $0-20$ & 10YR $3 / 3$ & $10 \mathrm{YR} 5 / 3$ & francoargilosa & $2 \mathrm{M} \mathrm{G} \mathrm{Bls}$ & $\mathrm{Md}$ & $\mathrm{MFi}$ & $\mathrm{Pl} \mathrm{Pe}$ & ab pl \\
\hline $\mathrm{BA}$ & $20-45$ & 10YR $3 / 2$ & 10YR $5 / 2$ & argila & $2 \mathrm{M} \mathrm{G} \mathrm{Bls}$ & $\mathrm{Ed}$ & Ef & Mt Pl Mt Pe & gr pl \\
\hline Btg & $45-70$ & 10YR $3 / 2$ & $10 \mathrm{YR} 5 / 2$ & argila & $3 \mathrm{G} \mathrm{Co} \mathrm{Bls}$ & $\mathrm{Ed}$ & Ef & Mt Pl Mt Pe & gr pl \\
\hline $\mathrm{BCg}$ & $70-90$ & $2,5 Y 3 / 2$ & $2,5 \mathrm{Y} 6 / 2$ & argila & 3 G Co Bls & Ed & Ef & Mt Pl Mt Pe & gr pl \\
\hline $\mathrm{Cg}$ & $90-120+$ & $2,5 \mathrm{Y} 6 / 1$ & $2,5 \mathrm{Y} 6 / 2$ & argila & $3 \mathrm{G} \mathrm{Co} \mathrm{Bls}$ & $\mathrm{Ed}$ & $\mathrm{Ef}$ & Mt Pl Mt Pe & - \\
\hline \multicolumn{10}{|c|}{ P2 - Planossolo Háplico eutrófico típico } \\
\hline A & $0-17$ & 10YR $3,5 / 3$ & 10YR 5/3 & franca & $2 \mathrm{M} \mathrm{Bls}$ & $\mathrm{Ld}$ & $\mathrm{Fi}$ & $\mathrm{Pl} \mathrm{Pe}$ & gr pl \\
\hline $\mathrm{E}$ & $17-20$ & 10YR 4,5/2 & 10YR 6/2 & franca & $2 \mathrm{M} \mathrm{Bls}$ & $\mathrm{Ld}$ & $\mathrm{Fi}$ & Lg Pl Lg Pe & $\mathrm{ab} \mathrm{pl}$ \\
\hline Btg1 & $20-30$ & 10YR $3 / 2$ & 10YR $4 / 2$ & francoargilosa & 3 G Blas Co & $\mathrm{Ed}$ & $\mathrm{Ef}$ & Mt Pl Mt Pe & gr pl \\
\hline Btg2 & $30-50$ & $10 \mathrm{YR} 5 / 1,5$ & 10YR 6/2 & francoargilosa & 3 G Blas Co & $\mathrm{Ed}$ & Ef & Mt Pl Mt Pe & gr pl \\
\hline $\mathrm{BCg}$ & $50-80$ & $2,5 \mathrm{Y} 5,5 / 1$ & $2,5 \mathrm{Y} 6 / 2$ & francoargilosa & 3 G Co Bls & $\mathrm{Ed}$ & $\mathrm{Ef}$ & Mt Pl Mt Pe & - \\
\hline \multicolumn{10}{|c|}{ P3 - Gleissolo Háplico Tb eutrófico solódico } \\
\hline $\mathrm{Ag}$ & $0-4$ & $2,5 \mathrm{Y} 3 / 1$ & $2,5 \mathrm{Y} 5 / 3$ & argilossiltosa & $2 \mathrm{M} \mathrm{Bls}$ & $\mathrm{Md}$ & Ef & Mt Pl Mt Pe & $\mathrm{cl} \mathrm{pl}$ \\
\hline $\mathrm{C} 1 \mathrm{~g}$ & $4-14$ & $2,5 \mathrm{Y} 4 / 2(\mathrm{am})$ & $2,5 \mathrm{Y} 5 / 3$ & argilossiltosa & $2 \mathrm{Ma} \mathrm{M}$ & Md & Ef & Mt Pl Mt Pe & cl ond \\
\hline $\mathrm{C} 2 \mathrm{~g}$ & $14-30$ & $2,5 \mathrm{Y} 5 / 2$ & $2,5 Y 5 / 2$ & argilossiltosa & $2 \mathrm{Ma} \mathrm{M}$ & $\mathrm{Md}$ & $\mathrm{Ef}$ & Mt Pl Mt Pe & $\mathrm{cl}$ ond \\
\hline $\mathrm{C} 3 \mathrm{~g}$ & $30-60+$ & $2,5 \mathrm{Y} 5 / 1$ & $2,5 \mathrm{Y} 5 / 2$ & argilossiltosa & $2 \mathrm{MaM}$ & $\mathrm{Md}$ & Ef & Mt Pl Mt Pe & - \\
\hline
\end{tabular}

(1) Cor: am-amassada; ${ }^{(2)}$ Transição. Estrutura: 2 - moderada. 3 -forte. M-média. G-grande. Bls-blocos subangulares. Blas - blocos angulares e subangulares. Co - colunar. Ma - maciça. Consistência: Ld - ligeiramente dura. Md - muito dura. Ed - extremamente dura. $\mathrm{Fi}$ - firme. $\mathrm{MFi}$ - muito firme. Ef - extremamente firme. $\tilde{\mathrm{n}}$ - não. Lg - ligeiramente. Mt - muito. $\mathrm{Pl}$ - plástica. Pe - pegajosa.

Transição: pl - plana. ond - ondulada. ab - abrupta. cl - clara.

A presença de horizonte E eluvial parece estar relacionada ao processo de ferrólise (van Ranst e Coninck, 2002), que provoca aparecimento de cores mais esbranquiçadas, expressas principalmente em razão da cor de partículas primárias nas frações areia e silte (Embrapa, 2013). Sua estrutura foi classificada como do tipo moderada e média com blocos subangulares, transicionando abruptamente para o horizonte Btg iluvial.

O horizonte C do perfil P3 foi subdividido em C1g, C2g e C3g, com espessura de $56 \mathrm{~cm}$ e textura argilossiltosa. O regime de hidromorfismo, mesmo que por curto período de tempo, foi revelado pelos mosqueados de cor ocre de radicelas encontrados no horizonte $\mathrm{C} 1 \mathrm{~g}$.

\section{Atributos físicos}

Os resultados granulométricos dos solos estudados apresentaram que os valores percentuais da areia grossa foram de duas a 14 vezes menores que os de areia fina, com tendência de redução de ambos em profundidade (Quadro 2). Os elevados teores de areia fina ocorreram nos perfis P1 e P2, o que possivelmente pode ser considerado importante para a confecção de artefatos cerâmicos, visto que não seria necessária a adição de nenhum tipo de aditivo (areia ou outros tipos de "barro") que funcione como atenuante de plasticidade e colabore no manuseio da pasta cerâmica, mas que não seja excessivamente pegajosa. Nos estudos realizados por Alves (2004) no Agreste paraibano, os ceramistas adicionavam areia, de maneira intuitiva à pasta cerâmica, como um atenuante de plasticidade durante seu processo de homogeneização, quando as peças tinham maior espessura em suas paredes para facilitar o manuseio, bem como aumentar a capacidade de resistência das vasilhas a rachaduras e rompimentos durante o processo de cocção. Embora seja aceitável que pouca quantidade de areia grossa, e maior de areia fina, possa melhorar as características da pasta cerâmica, não se sabe ao certo as proporções ideais de ambas as frações. Mesmo assim, de acordo com o observado nos Planossolos estudados, não seria necessária aplicação de antiplásticos à pasta cerâmica, em virtude da presença natural de atenuante de plasticidade.

O horizonte A de ambos os "barreiros" não é utilizado como matéria-prima para a confecção das peças artesanais. De acordo com os ceramistas, provavelmente é em razão dos maiores teores de areia em P1 e P2 (340 e $460 \mathrm{~g} \mathrm{~kg}^{-1}$, respectivamente), mesmo que o somatório dos teores das frações silte + argila ultrapasse os $500 \mathrm{~g} \mathrm{~kg}^{-1}$ (Quadro 2). No entanto, diferentemente do que ocorre nos Planossolos, o perfil P3 apresenta menos de $10 \mathrm{~g} \mathrm{~kg}^{-1}$ da fração 
Quadro 2. Atributos físicos dos perfis de solos utilizados na fabricação de cerâmica artesanal no distrito de Pasmado, município de Itaobim, Minas Gerais

\begin{tabular}{|c|c|c|c|c|c|c|c|c|}
\hline Horiz. & Prof. & $\begin{array}{c}\text { Areia } \\
\text { grossa }\end{array}$ & Areia fina & Silte & Argila & $\mathbf{A D A}^{(1)}$ & $\mathbf{G F}^{(2)}$ & $\begin{array}{r}\text { Silte/ } \\
\text { Argila }\end{array}$ \\
\hline & $\mathrm{cm}$ & \multicolumn{4}{|c|}{$\mathrm{g} \mathrm{kg}^{-1}$} & \multicolumn{2}{|c|}{$\%$} & \\
\hline \multicolumn{9}{|c|}{ P1 - Planossolo Háplico eutrófico típico } \\
\hline $\mathrm{A}$ & $0-20$ & 90 & 250 & 350 & 310 & 170 & 45 & 1,13 \\
\hline BA & $20-45$ & 50 & 110 & 270 & 570 & 420 & 26 & 0,47 \\
\hline Btg & $45-70$ & 40 & 100 & 340 & 520 & 410 & 21 & 0,65 \\
\hline $\mathrm{BCg}$ & $70-90$ & 40 & 130 & 340 & 490 & 360 & 27 & 0,70 \\
\hline $\mathrm{Cg}$ & $90-120+$ & 20 & 120 & 320 & 540 & 420 & 22 & 0,60 \\
\hline \multicolumn{9}{|c|}{ P2 - Planossolo Háplico eutrófico típico } \\
\hline $\mathrm{A}$ & $0-17$ & 30 & 430 & 350 & 190 & 110 & 42 & 1,84 \\
\hline $\mathrm{E}$ & $17-20$ & 60 & 400 & 360 & 180 & 90 & 50 & 2,00 \\
\hline Btg1 & $20-30$ & 40 & 250 & 360 & 350 & 290 & 17 & 1,03 \\
\hline Btg2 & $30-50$ & 40 & 270 & 330 & 360 & 300 & 16 & 0,92 \\
\hline $\mathrm{BCg}$ & $50-80$ & 80 & 330 & 270 & 320 & 270 & 16 & 0,84 \\
\hline \multicolumn{9}{|c|}{ P3 - Gleissolo Háplico Ta eutrófico solódico } \\
\hline $\mathrm{Ag}$ & $0-4$ & 20 & 40 & 480 & 460 & 380 & 17 & 1,04 \\
\hline C1g & $4-14$ & 20 & 50 & 510 & 420 & 330 & 21 & 1,21 \\
\hline $\mathrm{C} 2 \mathrm{~g}$ & $14-30$ & 10 & 40 & 480 & 470 & 450 & 4 & 1,02 \\
\hline C3g & $30-60+$ & 10 & 50 & 490 & 450 & 430 & 4 & 1,08 \\
\hline
\end{tabular}

(1) ADA: argila dispersa em água; ${ }^{(2)}$ GF: grau de floculação.

areia no horizonte A e valores acima de $900 \mathrm{~g} \mathrm{~kg}^{-1}$ de silte + argila (Quadro 2). Dessa forma, não basta somente ter altas quantidades das frações de menor diâmetro na composição granulométrica nos horizontes utilizados para cerâmica, mas que os teores de areia, principalmente a fina, possam estar em maiores quantidades, servindo como atenuante de plasticidade. Materiais minerais de origem aluvial proveniente de Neossolos Flúvicos de textura média (Alves, 2004) ou quartzo e vidro vulcânico (Arnold, 1971), ou ainda materiais orgânicos de origem vegetal ou animal (Leroi-Gourhan, 1984), ou partes de outros horizontes de Planossolos (Cabral, 2011), podem ser acrescidos à pasta cerâmica com a finalidade de reduzir sua plasticidade, mesmo que, em alguns casos, pela característica intrínseca do 'barro' não seja necessário.

Os valores de silte decresceram em profundidade, enquanto os de argila aumentaram para os perfis $\mathrm{P} 1$ e P2 (Quadro 2). Resultado semelhante foi observado por Cabral (2011) e Alves et al. (2007), os quais verificaram cerca de duas a seis vezes mais argila em relação ao silte na camada chamada "barro de louça", utilizada para a fabricação de peças de cerâmica no Agreste pernambucano e paraibano. Assim, tudo indica que a maior proporção de argila seja uma das razões da preferência desse material pelos ceramistas. É importante destacar que o aumento da fração silte promove redução da plasticidade e pegajosidade da pasta cerâmica (artesanato), o que facilita seu manuseio. Obviamente que a proporção ideal das frações areia, silte e argila para o "barro" de cerâmica é difícil de ser estabelecida e irá depender do tipo de argila envolvida.

Foram encontrados teores de argila com valores superiores a $500 \mathrm{~g} \mathrm{~kg}^{-1}$ no horizonte Btg do P1. A maior relação silte/argila no horizonte superficial indica que os processos de formação de argila no horizonte subsuperficial, como a formação de argila in situ, iluviação de argila do horizonte A para o B, destruição de argilas dos horizontes sobrejacentes e remoção preferencial de argilas dos horizontes superficiais, seriam os responsáveis pela formação do horizonte Btg (Parahyba, 1993; Oliveira, 2002; Oliveira et al., 2004).

As elevadas quantidades de argila dispersa em água (ADA), principalmente nos horizontes Btg dos Planossolos e C2g do Gleissolo, podem estar relacionadas a uma mineralogia mais micácea e aos maiores teores de $\mathrm{Na}^{+}$no complexo sortivo (Oliveira et al., 2003; Rengasamy, 1983), acarrentando menor grau de floculação das argilas.

Os valores do limite de liquidez (LL) foram mais elevados nos horizontes utilizados para a fabricação de cerâmica, principalmente no perfil P3 (Figura 2). As maiores proporções de argila presentes nesse perfil são responsáveis por isso, pois o LL é dependente dos constituintes minerais do solo, da intensidade das cargas de superfície, da espessura do filme de água e da relação da área de superfície ao volume ou à forma das partículas (Means e Parcher, 1963). 
Perfil 1 - P1 Limite de Atterberg (\%)

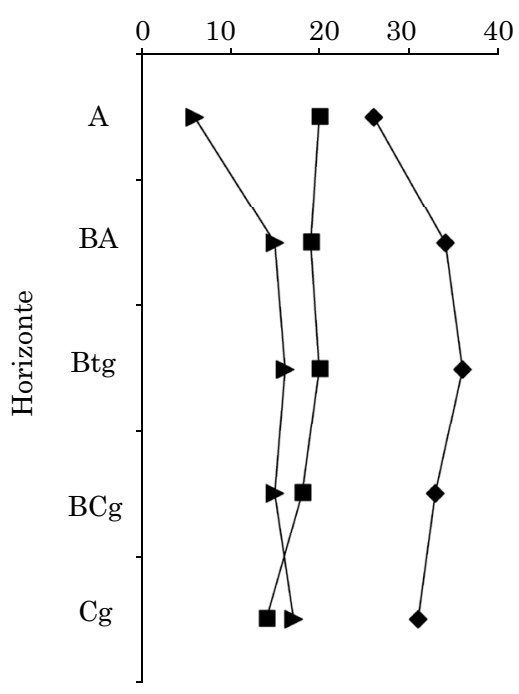

Perfil 2 - P2

Limite de Atterberg (\%)

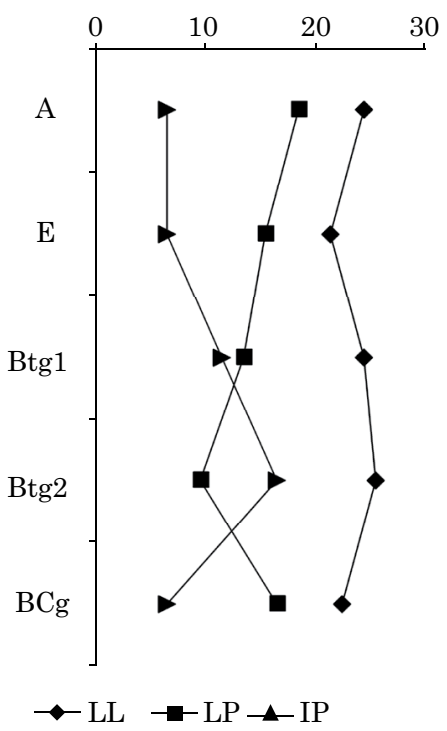

Perfil 3 - P3

Limite de Atterberg (\%)

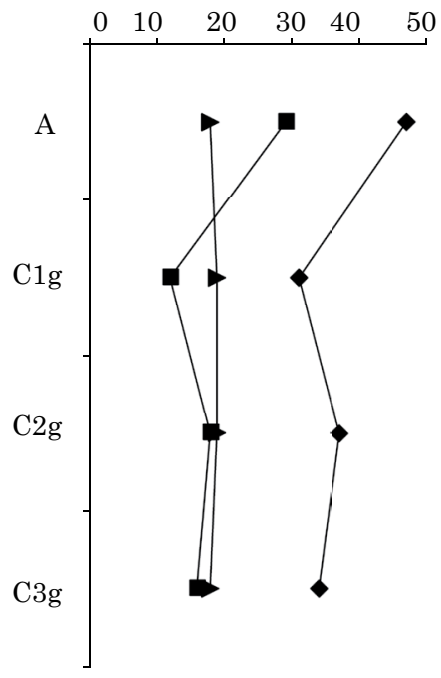

Figura 2. Limites de liquidez (LL) e plasticidade (LP) e índice de plasticidade (IP) dos perfis de solos utilizados na fabricação de cerâmica artesanal no distrito de Pasmado, município de Itaobim, Minas Gerais.

A grande uniformidade nos teores de argila dos horizontes $\mathrm{C} 1 \mathrm{~g}, \mathrm{C} 2 \mathrm{~g}$ e C3g do perfil P3 resultou em pequena diferença entre os valores de limite de plasticidade (LP), à exceção do horizonte A. De acordo com Smith et al. (1985), os teores de matéria orgânica aumentam a área superficial específica do solo, com acréscimo na retenção de água e consequente aumento nos valores de LP.

A relação positiva entre a CTC do solo e o limite de liquidez (LL) permite supor a associação entre o tipo dos minerais de argila com o potencial de expansão dos solos. Essa relação demonstra que os maiores valores de CTC ocasionaram incrementos nos valores de LL, aumentando a maior adsorção das moléculas de água às partículas do solo (indicados pelas setas) (Figura 3). Observou-se correlação positiva entre LL com argila $(r=0,72, p<0,01)$, silte $(r=0,51, p<0,01)$ e silte + argila $(r=0,85$, $\mathrm{p}<0,01)$, sugerindo que essas características estejam associadas.

A expansão dos solos é influenciada pelo tipo de argila, principalmente em razão da quantidade e do tipo de cátions trocáveis na superfície dos minerais de argila, bem como pelo excesso de carga negativa estrutural (Al-Rawas, 1998). O LL se incrementa com o aumento de minerais de argila expansivos (Yilmaz, 2006). Na fração argila dos solos estudados, não foi detectado nenhum tipo de mineral de argila expansivo, possivelmente por sua pouca expressão. Os horizontes usados para cerâmica apresentaram elevado índice de plasticidade (IP), indicando que esses materiais evidenciam boas características para seu uso na

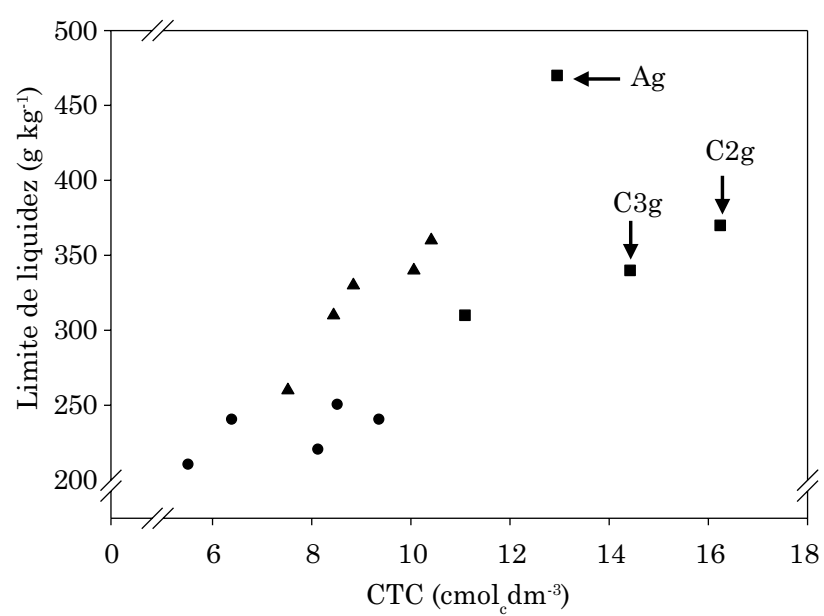

Figura 3. Relação entre capacidade de troca catiônica (CTC) e limite de liquidez (LL) dos horizontes dos perfis P1 ( $\Delta$ ), P2 ( • ) e P3 ( • ) de solos utilizados na fabricação de cerâmica artesanal no distrito de Pasmado, município de Itaobim, Minas Gerais. As setas indicam valores maiores de adsorção da água com as partículas do solo.

fabricação das peças artesanais. Esses horizontes foram classificados como mediamente plásticos (P1 e P2) e altamente plásticos (P3) (Figura 3).

Os ceramistas não utilizam o horizonte $\mathrm{Cg}$ do P1 para cerâmica por causa da sua consistência muito dura quando seco (Quadro 1), o que dificulta o manuseio durante as etapas iniciais da fabricação 
da cerâmica artesanal. A dureza é decorrente da ação conjunta de dois fatores: maiores quantidades de argila (>500 $\left.\mathrm{g} \mathrm{kg}^{-1}\right)$ e elevados teores de $\mathrm{Na}^{+}$ nesse horizonte. Entretanto, o índice de plasticidade (IP) do horizonte $\mathrm{Cg}$ foi superior aos dos horizontes normalmente utilizados para cerâmica (BA, Btg e $\mathrm{BCg}$ ), demonstrando que também possui boas características para ser usado como matéria-prima, principalmente pensando-se na disponibilidade do recurso solo para esse tipo de atividade, reconhecidamente escasso.

A camada do solo utilizada pelos ceramistas para a modelagem das peças de cerâmica engloba cerca de $60 \mathrm{~cm}$ de profundidade no "barreiro 1" e $50 \mathrm{~cm}$ no "barreiro 2", ou seja, os horizontes BA, Btg e BCg (P1); Btg1 e Btg2 (P2); e C2g e C3g (P3). Normalmente, os ceramistas designam o termo "barro bom" para indicar a camada considerada de melhor qualidade para a fabricação do artesanato. Nesse sentido, observou-se que nesses horizontes foram encontrados os maiores valores de LL e IP, confirmando a preferência desse material para a confecção das peças de cerâmica. De maneira geral, o material destinado à confeç̧ão de peças de cerâmica compreende principalmente o horizonte $\mathrm{B}$ textural de Planossolos Nátricos ou Háplicos, identificados por Cabral (2011), Alves et al. (2007) e Queiroz (1985) como "barro vermelho" ou "barro de loiça" nos Estados de Pernambuco, Paraíba e Ceará.
O "barreiro 2" (P3) apresenta grande uniformidade nos valores de IP em todos os horizontes do perfil. Contudo, a grande presença de raízes de gramíneas e os teores de matéria orgânica nos dois primeiros horizontes (Ag e C1g) ocasionam rompimento das peças ("pocar", termo usado pelos ceramistas) durante seu cozimento. A matéria orgânica influencia a característica de plasticidade dos solos, aumentando os limites de liquidez e plasticidade e reduzindo o índice de plasticidade (Chassefiere e Monaco, 1989), em razão da sua grande capacidade adsortiva de água (Malkawi et al., 1999).

\section{Fertilidade dos solos}

Os valores de $\mathrm{pH}$ indicaram solos com caráter ligeiramente ácido no horizonte superficial, com tendência ao aumento em profundidade (Quadro 3). O $\Delta \mathrm{pH}$ sempre negativo foi maior nos horizontes utilizados para cerâmica, sugerindo maior participação de minerais $2: 1$ na fração argila. Além disso, os baixos teores de $\mathrm{Al}^{3+} \mathrm{e}$ a presença de elevados teores de cátions favoreceram a manutenção de valores de $\mathrm{pH}$ mais elevados.

O complexo sortivo dos solos foi influenciado pela posição na paisagem e pelo material sedimentar dos quais são formados. Registrou-se que $\mathrm{Ca}^{2+}{\mathrm{e} \mathrm{Mg}^{2+}}^{2+}$ são os principais cátions responsáveis pelos valores da soma de bases (SB), com teores elevados desses

Quadro 3. Atributos químicos dos perfis de solos utilizados na fabricação de cerâmica artesanal no distrito de Pasmado, município de Itaobim, Minas Gerais

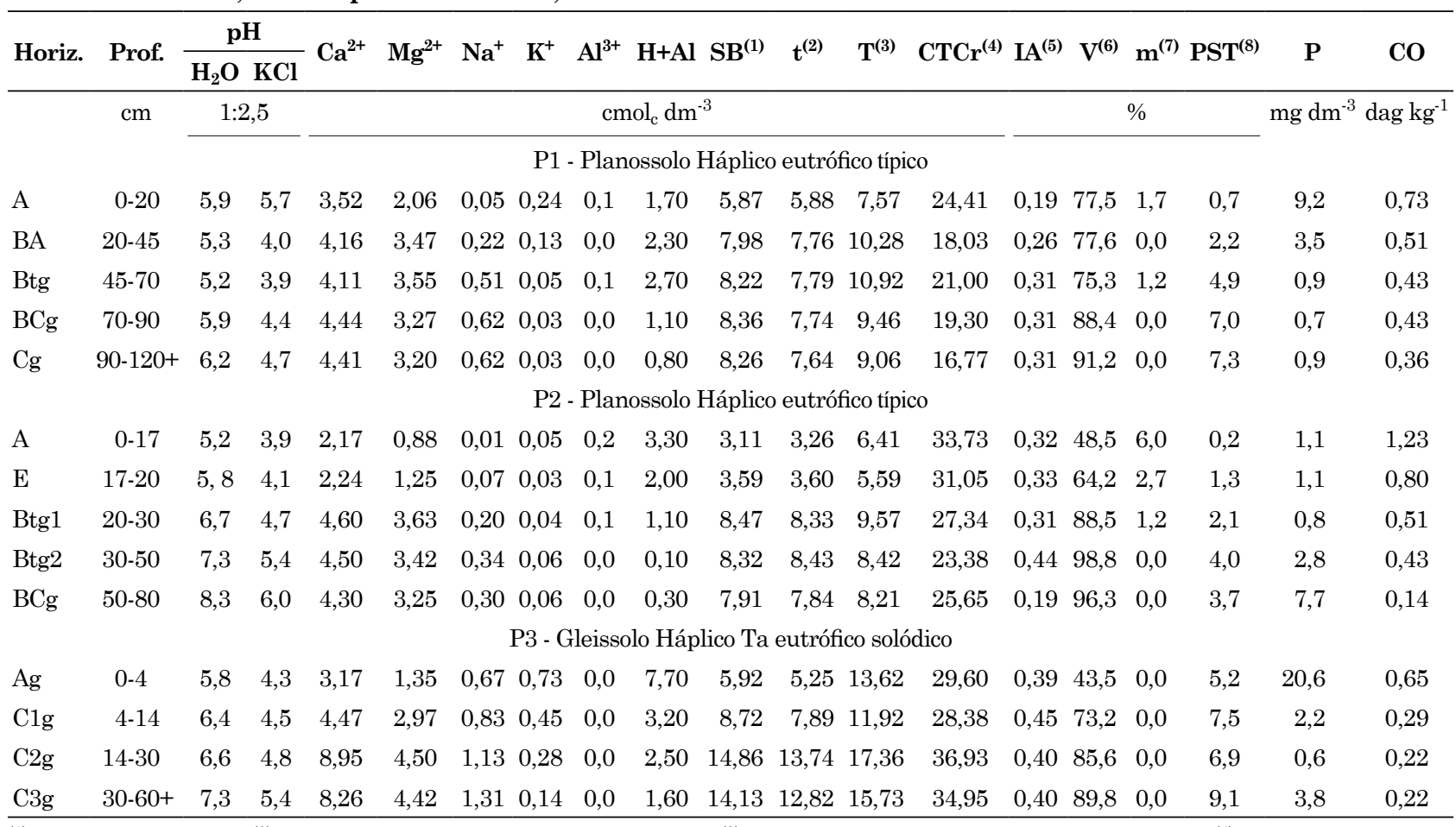

(1) SB: soma de bases; ${ }^{(2)}$ t: capacidade de troca catiônica efetiva; ${ }^{(3)} \mathrm{T}$ : capacidade de troca catiônica a pH 7,0; ${ }^{(4)} \mathrm{CTCr}$ : atividade da fração argila; ${ }^{(5)}$ IA: índice de atividade coloidal; ${ }^{(6)}$ V: saturação por bases; ${ }^{(7)}$ m: saturação por alumínio; ${ }^{(8)}$ PST: saturação por sódio. 
elementos, principalmente nos horizontes Btg (P1 e P2) e C2g (P3).

Todos os perfis estudados evidenciaram-se eutróficos, com maiores valores de CTC nos horizontes BA, Btg e BCg (P1), Btg1 e Btg2 (P2) e C2g e C3g (P3), coincidindo com seu uso na fabricação da cerâmica artesanal. Os valores de CTC são baixos, quando comparados com as mesmas classes de solos da região Nordeste do Brasil (Parahyba, 1993; Agbenin e Tiessen, 1995; Oliveira, 2007). Com valores de CTCr baixos, o perfil P3, ainda assim, foi classificado como Ta (argila de atividade alta). É conveniente ressaltar que a CTC da ilita (5 a $15 \mathrm{cmol}_{\mathrm{c}} \mathrm{kg}^{-1}$ ), originada nas zonas de perda de $\mathrm{K}$ das suas arestas, é baixa (Brown et al., 1978).

O índice de atividade coloidal (IA) nos solos estudados foi baixo, principalmente naqueles correspondentes ao "barreiro 1" (Quadro 3). As maiores atividades da fração argilosa foram encontradas no horizonte $\mathrm{C} 1 \mathrm{~g}$ do perfil P3. Contudo, para todos os horizontes, os valores de IA foram menores que 0,75 , sendo o solo considerado relativamente inativo, de acordo com Means e Parcher (1963); ou seja, a maior quantidade de argilominerais presentes na fração argila desses solos é de natureza caulinítica.

Diferentemente do ocorrido com o IA, os resultados para a atividade de argila (CTCr) (Embrapa, 1997) classificaram somente o perfil P3 como de atividade alta (Ta). O cálculo da capacidade de troca de cátions a $\mathrm{pH} 7,0\left(\mathrm{CTC}_{7,0}\right)$ é dependente da quantidade de cátions existentes na composição do mineral que está em equilíbrio com a solução do solo. A capacidade de hidratação de argilas varia com a quantidade e natureza dos cátions adsorvidos. Nesse particular, os maiores valores de soma de bases (SB) encontrados no perfil P3 provavelmente possuem relação direta influenciando sua classificação de atividade alta, não condizente com a mineralogia da fração argila composta por ilita e caulinita (Figuras 4 e 5).

O IA é uma relação empírica sobre o potencial de expansão dos solos, apresentando uma relação indireta com a densidade de cargas negativas do solo, enquanto a CTC do solo é uma medida direta da quantidade de cátions adsorvidos nas superfícies dos minerais de argila requeridos para neutralizar suas cargas negativas (Hardcastle, 2003). Dessa forma, o IA não se apresentou bom indicador na diferenciação da qualidade do "barro" utilizado para a cerâmica. Fabbri (1994) afirmou que a atividade coloidal de Skempton se baseia nos resultados dos limites de Atterberg, cujo material de solo usado para os ensaios é menor que $0,42 \mathrm{~mm}$, onde, além das frações argila e silte, também se encontra a fração areia, dependendo do seu tamanho. Esse fato poderia influenciar nos resultados de IA, não refletindo a verdadeira atividade da fração argila. Assim, o solo seria classificado como "inativo", ainda que possua características de "ativo".

Os teores de $\mathrm{Na}^{+}$foram baixos no horizonte superficial, com incremento em profundidade (Quadro 3). As maiores participações desse elemento conferiram ao perfil P3 o caráter solódico no $4^{\circ}$ nível categórico. A drenagem deficiente, o clima semiárido e o intemperismo de minerais sódicos (plagioclásios) na fração mais grosseira do solo parecem ser os principais fatores responsáveis pelo elevado índice de saturação de $\mathrm{Na}^{+}$desse solo (Corrêa et al., 2003). Os teores de $\mathrm{K}^{+}$e $\mathrm{P}$ disponíveis foram baixos para os solos de Minas Gerais (Alvarez V et al., 1999), decrescendo em profundidade. Nas áreas de Planossolos, além do seu uso com cerâmica, encontram-se pequenos cultivos de milho e feijão destinados ao consumo familiar.

$\mathrm{O}$ teor de C orgânico (CO) decresceu em profundidade, atingindo níveis menores que 2 dag $\mathrm{kg}^{-1}$ (Quadro 3). Os valores de $\mathrm{CO}$, ainda que baixos, poderiam atuar de forma negativa durante o processo de cocção da peça cerâmica. A presença de compostos de $\mathrm{C}$ juntamente com óxidos de $\mathrm{Fe}$ de argilas seriam os principais responsáveis pela incidência de "coração negro" em peças cerâmicas (Damiani et al., 2001). Em analogia ao coração negro, poder-se-ia pensar que possivelmente acontece o mesmo princípio, sem que haja escurecimento central da peça, e que a carbonização da matéria orgânica e produção de gases como $\mathrm{CO}_{2}$ possam reduzir suas características técnicas, como a resistência.

\section{Mineralogia dos solos}

Os solos utilizados para cerâmica P1, P2 e P3 apresentaram baixos teores de Fe extraído pelo DCB $\left(\mathrm{Fe}_{\mathrm{d}}\right)$ e oxalato de amônio $\left(\mathrm{Fe}_{\mathrm{o}}\right)$ nas temperaturas aplicadas (Quadro 4). Os baixos teores dos óxidos de Fe em Planossolos, decorrentes do processo de ferrólise pela oscilação dos ciclos de umedecimento e secagem e consequentemente redução $\left(\mathrm{Fe}^{2+}\right)$ e oxidação do íon $\mathrm{Fe}\left(\mathrm{Fe}^{3+}\right)$, promovem liberação de $\mathrm{H}^{+}$, deslocando os cátions básicos da estrutura dos argilominerais, dissolvendo argilas e causando gradiente textural pronunciado entre horizontes superficiais e subsuperficiais no perfil de solo (van Ranst e Coninck, 2002).

Os maiores teores de $\mathrm{Fe}_{\mathrm{o}}$ foram encontrados no horizonte A de todos os solos e em todas as temperaturas estudadas. Esse fato está em concordância com os resultados encontrados por Schwertmann (1985), indicando o papel da matéria orgânica, mesmo que em pequenas quantidades, como um dos principais inibidores da cristalinidade dos óxidos de $\mathrm{Fe}$ nos solos. Além disso, merece destaque a expressiva redução nos valores de $\mathrm{Fe}_{\mathrm{o}}$ com o aumento da temperatura, principalmente em P3, onde os valores se reduziram de 0,67 para 0,17 dag kg ${ }^{-1}$. 

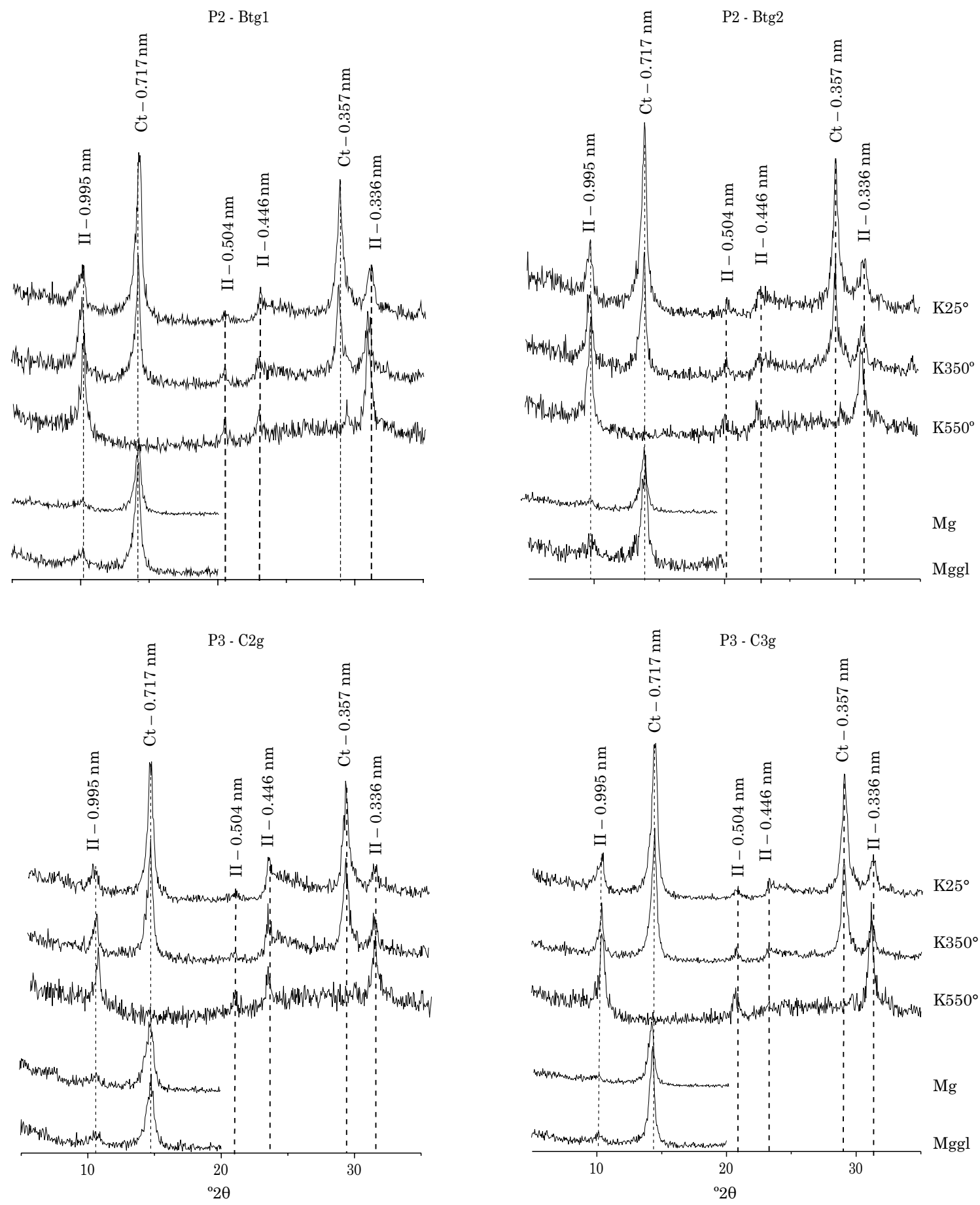

Figura 4. Difratograma de raios-X da fração argila desferrificada dos perfis P2 e P3 saturados com $\mathrm{K}$ (potássio) $\left(\mathrm{K}^{\circ} 5^{\circ}, \mathrm{K}_{550^{\circ}}, \mathrm{K}_{550}{ }^{\circ}\right.$ ), magnésio (Mg) e magnésio + etileno glicol (Mggl), utilizados na fabricação de cerâmica artesanal no distrito de Pasmado, município de Itaobim, Minas Gerais. (II-ilita e Ct-caulinita).

Os mais altos teores de $\mathrm{Fe}_{\mathrm{d}}$ proporcionaram uma relação $\mathrm{Fe}_{\mathrm{O}} / \mathrm{Fe}_{\mathrm{d}}$ baixa nas temperaturas de 350 e $550{ }^{\circ} \mathrm{C}$ (Quadro 4). Esses resultados estão de acordo com os observados por Sherman et al. (1964), os quais atribuíram às temperaturas as causas da redução na quantidade dos óxidos de $\mathrm{Fe}$ amorfos $\left(\mathrm{Fe}_{\mathrm{O}}\right)$ em razão do processo de desidratação e subsequente transformação para formas de maior cristalinidade. Resultados semelhantes foram encontrados por Juo et al. 
Quadro 4. Teores de Fe obtidos na TFSA nas temperaturas de $100{ }^{\circ} \mathrm{C}, 350{ }^{\circ} \mathrm{C}$ e $550{ }^{\circ} \mathrm{C}$ por extração com ditionito-citrato-bicarbonato de sódio $\left(\mathrm{Fe}_{2} \mathrm{O}_{3}\right.$-DCB) e oxalato de amônio $\left(\mathrm{Fe}_{2} \mathrm{O}_{3}\right.$-Ox.) e relações $\mathrm{Fe}_{2} \mathrm{O}_{3}-\mathrm{Ox} . / \mathrm{Fe}_{2} \mathrm{O}_{3}$-DCB dos perfis de solos utilizados na fabricação de cerâmica artesanal no distrito de Pasmado, município de Itaobim, Minas Gerais

\begin{tabular}{|c|c|c|c|c|c|c|c|c|c|c|c|c|}
\hline \multirow{2}{*}{ Horiz. } & \multicolumn{3}{|c|}{$\mathrm{Fe}_{2} \mathrm{O}_{3^{-}}-\mathrm{Ox}$} & \multicolumn{3}{|c|}{$\mathrm{Fe}_{2} \mathrm{O}_{3}-\mathrm{DCB}$} & \multicolumn{3}{|c|}{$\mathrm{Fe}_{2} \mathrm{O}_{3}-\mathrm{Ox} . / \mathrm{Fe}_{2} \mathrm{O}_{3}-\mathrm{DCB}$} & \multicolumn{3}{|c|}{ Cor } \\
\hline & $100{ }^{\circ} \mathrm{C}$ & $350^{\circ} \mathrm{C}$ & $550{ }^{\circ} \mathrm{C}$ & $100{ }^{\circ} \mathrm{C}$ & $350{ }^{\circ} \mathrm{C}$ & $550{ }^{\circ} \mathrm{C}$ & $100{ }^{\circ} \mathrm{C}$ & $350^{\circ} \mathrm{C}$ & $550{ }^{\circ} \mathrm{C}$ & $100{ }^{\circ} \mathrm{C}$ & $350{ }^{\circ} \mathrm{C}$ & $550{ }^{\circ} \mathrm{C}$ \\
\hline & \multicolumn{12}{|c|}{ dag $\mathrm{kg}^{-1}$} \\
\hline \multicolumn{13}{|c|}{ P1 - Planossolo Háplico eutrófico típico } \\
\hline A & 0,33 & 0,24 & 0,19 & 0,60 & 0,79 & 0,83 & 0,55 & 0,31 & 0,22 & $10 \mathrm{YR} 6 / 3$ & $10 \mathrm{YR} 5 / 4$ & 10YR 6/6 \\
\hline $\mathrm{BA}$ & 0,11 & 0,09 & 0,09 & 0,31 & 0,46 & 0,50 & 0,36 & 0,19 & 0,17 & 10YR $6 / 2$ & 10YR 6/2 & 10YR 7/6 \\
\hline Btg & 0,09 & 0,07 & 0,06 & 0,26 & 0,41 & 0,44 & 0,33 & 0,17 & 0,13 & 10YR 7/1 & 10YR 6/2 & 10YR $7 / 4,5$ \\
\hline $\mathrm{BCg}$ & 0,09 & 0,06 & 0,06 & 0,60 & 0,93 & 0,96 & 0,14 & 0,06 & 0,06 & 10YR $6 / 2$ & 10YR $6 / 3$ & 10YR $6 / 5$ \\
\hline $\mathrm{Cg}$ & 0,10 & 0,07 & 0,06 & 0,67 & 1,07 & 1,09 & 0,15 & 0,07 & 0,05 & 10YR $6 / 2$ & 10YR $6 / 4$ & 10YR 6/6 \\
\hline \multicolumn{13}{|c|}{ P2 - Planossolo Háplico eutrófico típico } \\
\hline A & 0,37 & 0,23 & 0,16 & 0,96 & 1,46 & 1,49 & 0,39 & 0,16 & 0,11 & 10YR $5 / 4$ & $7,5 \mathrm{YR} 5 / 6$ & $7,5 \mathrm{YR} 5 / 8$ \\
\hline $\mathrm{E}$ & 0,29 & 0,19 & 0,16 & 0,74 & 0,99 & 0,99 & 0,38 & 0,19 & 0,16 & $10 \mathrm{YR} 5 / 3$ & $7,5 \mathrm{YR} 5 / 4$ & 10YR $6 / 6$ \\
\hline Btg1 & 0,14 & 0,11 & 0,11 & 0,54 & 0,90 & 1,03 & 0,26 & 0,13 & 0,11 & 10YR $6 / 3$ & 10YR 5/4 & 10YR 6/6 \\
\hline Btg2 & 0,11 & 0,10 & 0,07 & 0,60 & 0,74 & 0,97 & 0,19 & 0,13 & 0,07 & 10YR $6,5 / 3$ & 10YR 5/4 & 10YR 6/6 \\
\hline $\mathrm{BCg}$ & 0,07 & 0,06 & 0,04 & 0,40 & 0,59 & 0,76 & 0,18 & 0,10 & 0,06 & $2,5 \mathrm{Y} 6 / 2$ & $2,5 \mathrm{Y} 6 / 3$ & 10YR 6/6 \\
\hline \multicolumn{13}{|c|}{ P3 - Gleissolo Háplico Ta eutrófico solódico } \\
\hline $\mathrm{Ag}$ & 0,67 & 0,59 & 0,17 & 0,80 & 1,19 & 1,76 & 0,84 & 0,49 & 0,10 & $2 \mathrm{Y} 5 / 3$ & $2,5 \mathrm{Y} 5 / 3$ & $7,5 \mathrm{YR} 5 / 8$ \\
\hline C1g & 0,57 & 0,34 & 0,17 & 1,17 & 1,97 & 2,51 & 0,49 & 0,17 & 0,07 & $2 \mathrm{Y} 6 / 4$ & 10YR 5/4 & $7,5 \mathrm{YR} 5 / 8$ \\
\hline $\mathrm{C} 2 \mathrm{~g}$ & 0,40 & 0,21 & 0,19 & 1,11 & 1,60 & 1,89 & 0,36 & 0,13 & 0,10 & $2 \mathrm{Y} 6 / 3$ & 10YR 6/4 & 10YR 6/6 \\
\hline C3g & 0,19 & 0,14 & 0,14 & 0,79 & 1,14 & 1,31 & 0,24 & 0,13 & 0,11 & $2 \mathrm{Y} 6 / 2$ & $2,5 \mathrm{Y} 6 / 3$ & 10YR 6/6 \\
\hline
\end{tabular}

(1974), em condições naturais, com altas temperaturas e períodos prolongados de seca (quatro a cinco meses) em solos da Nigéria. Ainda que predominem formas de melhor cristalinidade com aplicação de temperaturas mais elevadas, é desconhecida sua contribuição para a qualidade final da cerâmica, como, em relação à resistência das peças ao rompimento.

Com a elevação da temperatura, óxidos de Fe como lepidocrocita, goethita, hematita e formas amorfas de Fe poderiam modificar-se em maghemita na presença de compostos orgânicos (Resende, 1976; Schwertmann, 1985). Mesmo assim, nos perfis estudados, não foi verificada presença de magnetização nas amostras em razão das temperaturas avaliadas.

Os minerais presentes na fração argila dos três solos são constituídos de caulinita e ilita (Figuras 4 e 5). Todos os perfis apresentaram caulinita com picos a 0,715 e $0,357 \mathrm{~nm}$ nas amostras saturadas com K (com e sem aquecimento), com $\mathrm{Mg}$ e $\mathrm{Mg}+$ etileno glicol, e que desaparecem no tratamento com $\mathrm{K}$ aquecido a $550{ }^{\circ} \mathrm{C}$. O predomínio de caulinita é muito expressivo em todos os solos, condizente com os baixos teores de CTC da fração argila, onde aparecem picos bem-pronunciados, indicando melhor cristalinidade desse mineral. A natureza mineralógica de Planossolos pode variar de essencialmente caulinítica até predominantemente esmectítica, apresentando minerais expansivos ou não (caso da ilita), ou evidenciando mistura de ambos, principalmente em condições semiáridas (Oliveira, 2003).

A pedogênese de argilominerais expansivos 2:1 (esmectita, vermiculita e o grupo das micas) é favorecida em solos que apresentam impedimento à drenagem, como nos solos de baixada hidromórficos. No entanto, além desses minerais secundários, podem ainda ser encontrados interestratificados irregulares de minerais 1:1 e 2:1 (Alves, 2004; Cabral, 2011), não observados neste estudo. A natureza caulinítica e a ilítica da fração argila dos Planossolos e Gleissolos estudados conferem características satisfatórias à pasta cerâmica, desde o processo de retirada do 'barro' à cocção das peças na etapa final. É importante ressaltar que, mesmo em pequenas proporções, a presença de minerais de argila 2:1 expansivos nos solos influenciam seus atributos físicos e químicos, além da expressão de feições morfológicas típicas, tão características a esses argilominerais (Azevedo e Vidal-Torrado, 2009). 
$\mathrm{P} 1$ - A

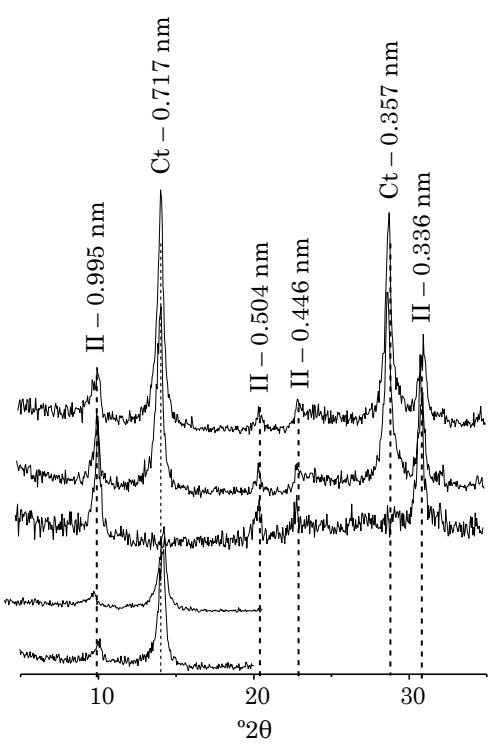

P1 - Btg

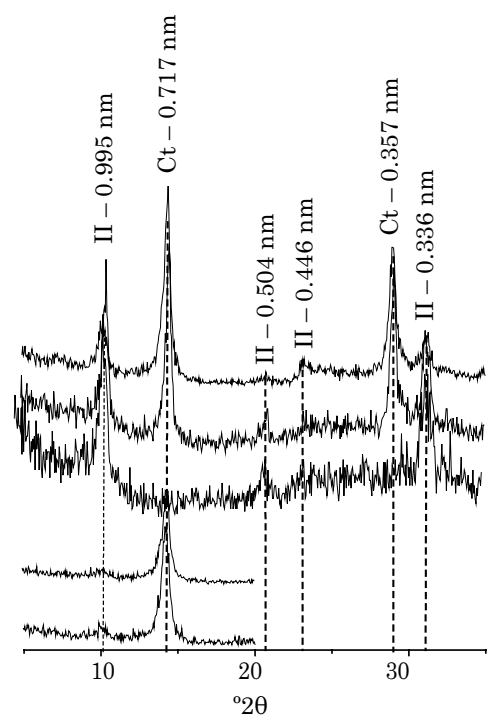

$\mathrm{P} 1$ - Cg

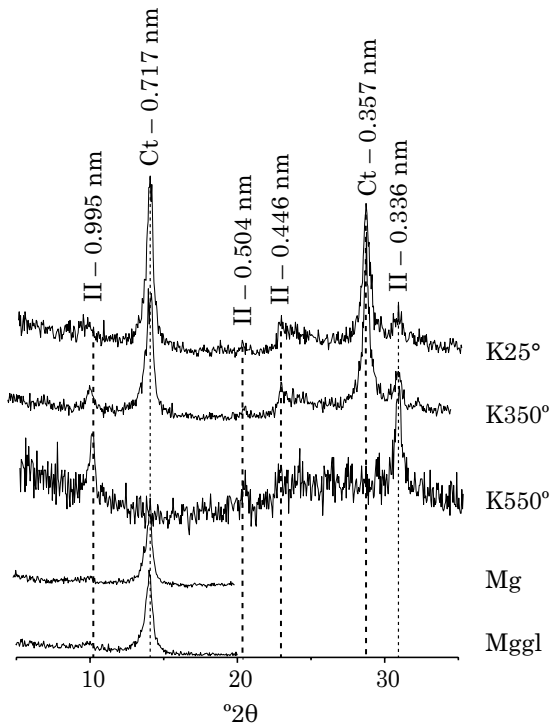

Figura 5. Difratograma de raios-X da fração argila desferrificada do perfil P1 saturada com

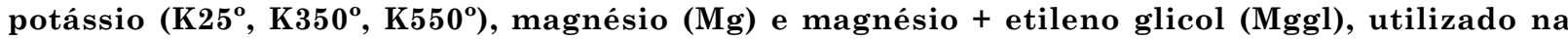
fabricação de cerâmica artesanal no distrito de Pasmado, município de Itaobim, Minas Gerais. (II-ilita e Ct-caulinita).

\section{CONCLUSÕES}

Os horizontes BA, Btg e BCg do perfil P1; Btg1 e Btg2, do P2; e C2g e C3g, do P3 apresentaram as maiores proporções de argila e silte e os índices de plasticidade e de atividade coloidal que mais condizem com a seleção do "barro" pelos ceramistas.

As maiores quantidades de areia e matéria orgânica no horizonte A de todos os perfis dos 'barreiros' justificam o fato dos ceramistas considerá-los impróprios para a fabricação da cerâmica.

As quantidades de areia fina pareceram suficientes para promover efeito "não plástico", contribuindo para melhor qualidade do barro e, consequentemente, da cerâmica.

O tipo e a proporção da argila encontrados nos solos dificultou o estabelecimento da proporção ideal das frações areia, silte e argila e a porcentagem de matéria orgânica na definição de um bom material para cerâmica.

Não se justifica o descarte do horizonte $\mathrm{Cg}$ do perfil $\mathrm{P} 1$, em razão das suas características físicas, mineralógicas e índice de plasticidade favoráveis para a confecção dos artefatos artesanais.

A relação $\mathrm{Fe}_{\mathrm{O}} / \mathrm{Fe}_{\mathrm{d}}$ reduziu com o aquecimento, mas não se pode inferir a respeito da influência da maior proporção das formas de ferro mais cristalinas na qualidade final da cerâmica, sobretudo em sua resistência.

\section{REFERÊNCIAS}

Agbenin JO, Tiessen H. Soil properties and their variations on two contiguous hillslopes in Northeast Brazil. Catena. 1995;24:147-61.

Al-Rawas AA. The factors controlling the expansive nature of the soils and rocks of northern Oman. Eng Geol. 1998;53:327-50.

Alvarez V VH, Novais RF, Barros NF, Cantarutti RB, Lopes AS. Interpretação dos resultados das análises de solos. In: Ribeiro AC, Guimarães PTG, Alvarez V VH, editores. Recomendação para o uso de corretivos e fertilizantes em Minas Gerais. $5^{\mathrm{a}}$.ed. Viçosa, MG: Comissão de Fertilidade do Solo do Estado de Minas Gerais; 1999. p.25-42.

Alves AGC. Do "barro de loiça" à "loiça de barro": Caracterização etnopedológica de um artesanato camponês no Agreste Paraibano [tese]. São Carlos: Universidade Federal de São Carlos; 2004.

Alves AGC, Marques JGW, Queiroz SB, Silva IF, Ribeiro MR. Caracterização etnopedológica de Planossolos utilizados em cerâmica artesanal no Agreste Paraibano. R Bras Ci Solo. 2005;29:379-88.

Alves AGC, Queiroz SB, Silva IF, Ribeiro MR. Sodium-affected Alfisols of the agreste region, state of Paraiba, Brazil, as known by potter-farmers and agronomists. Sci Agric. 2007;64:495-505.

Amaral FCS, Santos HG, Áglio MLD, Duarte MN, Pereira NR, Oliveira RP, Carvalho Júnior W. Mapeamento de solos e aptidão agrícola das terras do Estado de Minas Gerais. Rio de Janeiro: Embrapa Solos; 2004.

Agência Nacional das Águas - ANA. Sistemas de informações hidrológicas. [Acesso em: 10 nov 2001]. Disponível em: http:// hidroweb.ana.gov.br/. 
Arnold DE. Ethnomineralogy of Ticul, Yucatan potters: Etics and emics. Am. Antiquity. 1971;36:20-40.

Associação Brasileira de Normas Técnicas - ABNT. NBR 6459/84 Solo: Determinação do limite de liquidez. Rio de Janeiro: 1984a.

Associação Brasileira de Normas Técnicas - ABNT. NBR 7180/84 Solo: Determinação do limite de plasticidade. Rio de Janeiro: 1984b.

Azevedo AC, Vidal-Torrado P. Esmectita, vermiculita, minerais com hidroxi entre camadas e clorita. In: Melo VF, Alleoni LRF, editores. Química e mineralogia do solo. Viçosa, MG: Sociedade Brasileira de Ciência do Solo; 2009. p.381-426.

Barrera-Bassols N, Zinck JA. Ethnopedology: A worldwide view on the soil knowledge of local people. Geoderma. 2003;111:171-95.

Barrios E, Trejo MT. Implications of local soil knowledge for integrated soil management in Latin America. Geoderma. 2003;111:217-31.

Brasil. Ministério da Agricultura. Levantamento de reconhecimento dos solos da Zona do Médio Jequitinhonha - Minas Gerais. Rio de Janeiro: Equipe de Pedologia e Fertilidade do Solo, 1970.

Brasil. Ministério de Minas e Energia. Secretaria Geral. Projeto RADAMBRASIL. Folha SE 24 Rio Doce: Geologia, geomorfologia, pedologia, vegetação e uso potencial da terra. Rio de Janeiro: 1987.

Browman DL, Gundersen JN. Altiplano comestible earths: Pre-historic and historic geography of highland Peru and Bolivia. Geoarchaeology. 1993;8:413-25.

Brown G, Newman ACD, Rayner JH, Weir AH. The structures and chemistry of soil clay minerals. In: Greenland DJ, Hayes MH, editors. The chemistry of soil constituents. Chichester: John Wiley \& Sons; 1978. p.29-178.

Bueno FS. Dicionário da língua portuguesa. São Paulo: Lisa; 1985.

Cabral RL. Uso e conhecimento do solo por artesãos camponeses no Agreste Pernambucano: Uma abordagem etnopedológica [dissertação]. Recife: Universidade Federal Rural de Pernambuco; 2011.

Caputo HP. Mecânica dos solos e suas aplicações. 6 a .ed. Rio de Janeiro: LTC; 1994.

Cardoso I, Resende M. Percepção e uso de ambientes naturais por pequenos agricultores. Alternativas: Cad Agroecol. 1996;4:18-21.

Chassefiere B, Monaco A. Role of organic matter and particle fabric in mass-physical and geotechnical properties: implications for undrained slumping in Aegean Sea and Ionian Sea modern sediments. Mar Geol. 1989;87:165-82.

Corrêa MM, Ker JC, Mendonça ES, Ruiz HA, Bastos RS. Atributos físicos, químicos e mineralógicos de solos da região das várzeas de Souza (PB). R Bras Ci Solo. 2003;27:311-24.

Correia JR, Lima ACS, Anjos LHC. O trabalho do pedólogo e sua relação com comunidades rurais: observações com agricultores familiares no Norte de Minas Gerais. Cad Ci Tecnol. 2004;21:447-67.

Correia JR, Anjos LHC, Lima ACS, Neves DP, Toledo LO, Calderano Filho B, Shinzato E. Relações entre o conhecimento de agricultores e de pedólogos sobre solos: Estudo de caso em Rio Pardo de Minas, MG. R Bras Ci Solo. 2007;31:1045-57.
Companhia de Pesquisa de Recursos Minerais - CPRM. Projeto cadastro de abastecimento por águas subterrâneas, Estados de Minas Gerais e Bahia: Diagnóstico do município de Itaobim, MG. Belo Horizonte: 2004.

Damiani JC, Perez F, Melchiades FG, Boschi AO. Coração negro em revestimentos cerâmicos: principais causas e possíveis soluções. Cerâmica Indust. 2001;6:12-6.

Empresa Brasileira de Pesquisa Agropecuária - Embrapa. Centro Nacional de Pesquisa de Solos. Manual de métodos de análise de solo. $2^{\text {a }}$.ed. Rio de Janeiro: Embrapa Solos; 1997.

Empresa Brasileira de Pesquisa Agropecuária - Embrapa. Centro Nacional de Pesquisa de Solos. Sistema brasileiro de classificação de solos. $3^{\text {a }}$.ed. Rio de Janeiro: Embrapa Solos; 2013.

Fabbri GTP. Caracterização da fração fina de solos tropicais através da adsorção de azul de metila [tese]. São Carlos: Universidade Federal de São Carlos; 1994. [Acesso 16 jun 2015]. Disponível em: http://www.teses.usp.br/teses/ disponiveis/18/18137/tde-06112012-104943/

Hardcastle JH. Evaluation and treatment of expansive volcanic soils US95, Owyhee County, Idaho. Moscow: University of Idaho; 2003.

Juo ASR, Moormann FR, Maduakor HO. Forms and pedofenetic distribuition of extractable iron and aluminum in selected soils of Nigeria. Geoderma. 1974;11:167-79.

Leroi-Gourhan A. Evolução e técnicas. $2^{\mathrm{a}}$.ed. Lisboa: Setenta; 1984.

Malkawi AIH, Alawneh AS, Abu-Safaqah OT. Effects of organic matter on the physical and the physicochemical properties of an illitic soil. Appl Clay Sci. 1999;14:257-78.

McKeague JA, Day JH. Dithionite and oxalate extractable Fe and $\mathrm{Al}$ as aid in differentiating various classes of soils. Can J Soil Sci. 1966;46:13-22.

Means RE, Parcher JV. Physical properties of soils. Ohio: Merrill; 1963.

Mehra OP, Jackson ML. Iron oxide removal from soils and clay by a dithionite-citrate system buffered with sodium bicarbonate. Clay Miner. 1960:7:317-27.

Oliveira LB. Solos Planossólicos do Sertão do Araripe: caracterização, classificação e gênese [dissertação]. Recife: Universidade Federal Rural de Pernambuco; 2002.

Oliveira LB, Ribeiro MR, Ferraz FB, Jacomine PKT. Classificação de solos Planossólicos do Sertão do Araripe (PE). R Bras Ci Solo. 2003;27:685-93.

Oliveira LB, Ribeiro MR, Ferraz FB, Ferreira MGVX, Mermut AR. Mineralogia, micromorfologia e gênese de solos Planossólicos do sertão do Araripe, Estado de Pernambuco. R Bras Ci Solo. 2004;28:665-78.

Oliveira LB. Mineralogia, micromorfologia, gênese e classificação de Luvissolos e Planossolos desenvolvidos de rochas metamórficas no semiárido do Nordeste Brasileiro [tese]. Viçosa, MG: Universidade Federal de Viçosa; 2007.

Ollier CD, Drover DP, Godelier M. Soil knowledge amongst the Baruya of Wonenara, New Guinea. Oceania. 1971;42:33-41.

Osbahr H, Allan C. Indigenous knowledge of soil fertility management in southwest Niger. Geoderma. 2003;111:457-79. 
Parahyba RBV. Gênese de solos Planossólicos do Agreste de Pernambuco [dissertação]. Recife: Universidade Federal Rural de Pernambuco; 1993.

Queiroz JS, Norton BE. An assessment of an indigenous soil classification used in the caatinga region of Ceará State, Northeast Brazil. Agric Syst. 1992;39:289-305.

Queiroz JS. The Acarau Valley in Northeast Brazil: Vegetation, soils and land-use [these]. Logan: Utah State University; 1985.

Rengasamy P. Clay dispersion in relation to changes in the electrolyte composition of dialysed red-brown earths. J Soil Sci. 1983;34:723-32.

Resende M. Mineralogy, chemistry, morphology and geomorphology of some soils of the Central Plateau of Brazil [tese]. Purdue: University Purdue; 1976.

Santos RD, Lemos RC, Santos HG, Ker JC, Anjos LHC. Manual de descrição e coleta de solo no campo. $5^{\text {a }}$.ed. Viçosa, MG: Sociedade Brasileira de Ciência do Solo; 2005.

Scatolini FM, Moniz AC. Influência do material de origem do lençol freático e da posição topográfica nos solos de uma encosta em Mococa (SP). R Bras Ci Solo. 1992;16:379-88.

Schaefer CEGR, Marques FASM, Campos JCF. Origens da pedologia no Brasil: Resenha histórica. Geonomos. 1997;5:1-15.
Schwertmann U. The effect of pedogenic environments on iron oxide minerals. Adv Soil Sci. 1985;1:171-200.

Sherman GD. Matsusaka Y, Ikawa H, Uehara G. The role of amorphous fraction in the properties of tropical soils. Agrochimica. 1964;7:146-63.

Skempton AW. The colloidal activity of clays. In: Proceedings of the $3^{\text {rd }}$. International Conference Soil Mechanics Found Engineer; 1953; Zurich. Zurich: International Society of Soil Mechanics and Geotechnical Engineering; 1953. p.57-61.

Smith CW, Hadas A, Dan J, Koyumdjisky H. Shrinkage and Atterberg limits in relation to other properties of principal soil types in Israel. Geoderma. 1985;35:47-65.

Talawar S, Rhoades RE. Scientific and local classification and management of soils. Agric Human Values. 1998;15:3-14.

van Ranst E, Coninck F. Evaluation of ferrolysis in soil formation. Eur J Soil Sci. 2002;53:513-19.

Whitting LD, Allardice WR. X ray diffraction techniques. In: Kluter A, editor. Methods of soil analysis: Physical and mineralogical properties. $2^{\text {nd }}$.ed. Madison: American Society of Agronomy; 1986. Pt 1. p.331-62.

Yilmaz, I. Indirect estimation of the swelling percent and a new classification of soils depending on liquid limit and cation exchange capacity. Eng Geol. 2006;85:295-301. 